\title{
ФИНАНСИРОВАНИЕ ПОЛИТИЧЕСКИХ ПАРТИЙ: ПОНЯТИЕ, ВИДЫ, ОСОБЕННОСТИ
}

\begin{abstract}
Аннотация: Автор считает, что на законодательном уровне вопросам партийного финансирования не уделяется должного внимания. В законодательстве Российской Федерации отсутствует определение соответствующего понятия. Автор считает для развития прозрачности партийного финансирования, как способа борьбы с политической коррупиией, необходимо не только выявить существуюшие пробель законодательного регулирования, но и способствовать дальнейтему развитию законодательства в области регулирования финансирования политических партий с иелью его совершенствования. Автор считает, что сегодня российское законодательство в области регулирования финансирования политических партий во многом соответствует международным нормам и стандартам. Однако оно характеризуется громоздкостью, в том смысле, что данные вопросы регулируются значительным количеством различных нормативно-правовых актов, что в свою очередь приводит к определенным трудностям правоприменения. Более того, различия между различными способами и видами партийного финансирования, а также их нормативного регулирования представляются значительными. В свзяи с этим автор считает иелесообразным разработать единый нормативно-правовой акт, сферой регулирования которого стали бы вопросы партийного финансирования.
\end{abstract}

Abstract: The legislature is being neglectful in relation to party financing. The legislation of the Russian Federation lacks a definition of the corresponding concept. In order to promote the transparency of party financing as a way to fight political corruption, it is necessary not only to identify gaps in legal regulation, but also to perfect such regulation by encouraging the further development of legislation controlling the financing of political parties. Russian legislative controls over the financing of political parties are largely consistent with international norms and standards. However, they are cumbersome, in the sense that these issues are regulated by a substantial number of different laws, which in turn leads to difficulties of enforcement. Moreover, there are significant differences between the various types and methods of party financing, as well as between the various applicable laws. In this regard, it is appropriate for a single piece of legislation to be developed, the scope of which covers all issues in relation to financing of political parties.

Ключевые слова: политические партии, цели деятельности партий, текущая деятельность партий, партийное финансирование, виды партийного финансирования, текущее финансирование партий, избирательные фонды, источники партийного финансирования, пожертвования, ограничение размеров пожертвований Keywords: political parties, aims of party activities, the current activities of political parties, party funding, types of party financing, current financing of political parties, electoral funds, sources of party funding, donations, limits on the size of donations

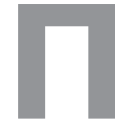
олитические партии являются важным институтом гражданского общества, представляя собой своего рода связующее звено между государством и гражданами. Законодательством России предусмотрен ряд целей деятельности политических партий, среди которых участие в выборах, формирование общественного мнения, политическое и идеоло- гическое воспитание граждан, а также представительство интересов граждан в органах государственной власти. Представляется очевидным, что участие в выборах является основной целью деятельности партий. Однако без достижения иных целей деятельности, невозможным становится достижение положительных результатов при участии в выборах. Таким образом, 
DOI: $10.7256 / 1811-9018.2013 .11 .9855$

При цитировании этой статьи сноска на доі обязательна

\section{Право и политика $11(166) \cdot 2013$}

остальные цели деятельности партий могут быть рассмотрены в качестве обеспечительных. Деятельность, направленная на их достижение может быть определена как текущая деятельность политических партий. Между тем, для эффективного осуществления своей деятельности, в том числе текущей, политические партии нуждаются в значительных финансовых ресурсах. Как считает Ю.А.Юдин: «Взаимосвязь денег и политики - явление, присущее политической жизни на всех этапах развития государственности» ${ }^{1}$. Однако в настоящее время вопрос финансирования политических партий стал особенно остро в Российском обществе, что обусловлено существованием нескольких причин. Прежде всего, речь идет об увеличении издержек на проведение избирательных кампаний, в том числе на возможность доступа к СМИ и иное, что связано с изменением политических технологий и методов политической борьбы. Партии вынуждены прибегать к современным и дорогостоящим методом и средствам политической конкуренции, так как без этого они бы потеряли возможность получить доступ к публичной власти. Во - вторых, в настоящее время мы являемся свидетелями либерализации процесса создания новых политических партий. До внесения поправок в соответствующую статью Федерального закона о политических партий, предусматривающую минимальное количество членов партии для ее создания устанавливалось в размере не менее сорока тысяч членов партии. С принятием Федерального закона от 02.04.2012 № 28-Ф3 «О внесении изменений в Федеральный закон «О политических партиях"»" требование к минимальному количеству членов политической партии для ее создание сократилось в 20 раз до 500 человек. Подобные изменения неизбежно привели к резкому увеличению числа политических партий в России. В свою очередь появление значительного числа (более 70 по состоянию на сентябрь 2013 года) $)^{3}$ вновь созданных политических партий способствует не только развитию политической конкуренции, а также развитию и обострению конкуренции партий при привлечении необходимых финансовых средств. Особенно остро подобная конкуренция отразится на борьбе за привлечения средств из таких источников финансирования, как пожертвования, которые составляют основу бюджетов политических партий согласно их сводным финансовым отчетам.

\footnotetext{
${ }^{1}$ Юдин Ю.А. Политические партии и право в современном государстве. М.: ФОРУМ: ИНФРА-М. 1998. - С.144

${ }^{2}$ См.: СЗ РФ. 09.04.2012. № 15. Ст. 1721

${ }^{3}$ http://minjust.ru/nko/gosreg/partii/spisok
}

Учитывая данные факты, отсутствие надлежащего правового регулирования вопросов финансирования политических партий и контроля соблюдения законодательства в данной части со стороны государства может привести к увеличению политической коррупции, что негативным образом скажется на возможности надлежащего развития гражданского общества в стране в целом. Стоит также указать, что вопросам финансирования политических партий уделено немало внимания, однако основной упор делается на финансирование партий в связи с их участием в выборах. Однако, как говорилось выше, партии осуществляют свою деятельность ежедневно, а участие в выборах - это лишь одна из целей их деятельности, хотя и основополагающая.

Несмотря на важность вопросов финансирования политических партий в законодательстве соответствующее понятие не раскрывается. В общем смысле под финансированием понимается обеспечение денежными ресурсами текущих затрат и капитальных вложений, которые осуществляются за счет собственных средств, государства, привлеченных, заемных и иных. ${ }^{4}$ В отношении финансирования политических партий заслуживает внимание определение указанного понятия, предложенное Романенко О.В. Под финансированием политической партии предлагается понимать финансовое и поддающееся финансовой оценке материальное обеспечение ее деятельности, выгоды, полученные в результате освобождения от возникающих по общему правилу обязательств и другие действия, прямо или косвенно направленные на достижение партийных целей. Данное понятие наиболее проработано, автор постарался подробно и детально его раскрыть, однако оно характеризуется несколько сложной для понимания структурой, громоздкостью. Более того, данное определение не содержит разделения финансирования текущей деятельности и деятельности политических партий в процессе проведения избирательных кампаний. В этой связи представляется более корректным определение финансирования политических партий, предложенное испанским правоведом Сантьяго Гонзалес-Марас, согласно которому финансирование политических партий является предоставление финансово экономических ресурсов (частных и государственных) необходимых для осуществления текущей деятельности и предвыборной кампании при проведения выборов 5 . Хотя в данное определение стоит внести коррективы

\footnotetext{
${ }^{4}$ www.difinicion.org/financiamiento

${ }^{5}$ Cм.: Santiago Gonzalez-Maras, La financiación de los partidos politicos. Madrid. Dykinson. 1995. p.21-23
} 


\section{Системы стабилизации: финансовый контроль}

в связи с тем, что наряду с прямым финансированием политических партий, законодательством России предусматривается и косвенное финансирование. Так, как видится автору, финансирование политических партий следует понимать, как предоставление политическим партиям финансово экономических ресурсов (частных и государственных), а также привилегий и иных благ, поддающихся финансовой оценке, необходимых для осуществления текущей деятельности и предвыборных кампаний на выборах различных уровней.

Важность разделения понятий финансирования избирательных кампаний и текущей деятельности политических партий заключается в наличие принципиальных отличий между ними, что не однократно подчеркивалось в научных исследованиях. Как указывают И. Борисов, С. Заславский, серьезные различия в порядке финансирования деятельности политических партий в меж выборный период и в период проведения избирательных кампаний существуют по следующим аспектам:

- По источникам поступлений;

- По их предельному размеру;

- По возможности их использования ${ }^{6}$.

В отношении регулирования источников финансирования избирательных кампаний законодательство в значительной мере более строгое, нежели финансирования текущей деятельности. Согласно Федеральному закону от 12.06.2002 N 67-Ф3 (ред. от 02.07.2013) «Об основных гарантиях избирательных прав и права на участие в референдуме граждан Российской Федерации» избирательные фонды политических партий формируются за счет:

- собственных средств;

- $\quad$ за счет средств политической партии, выделяемых кандидату, выдвинутому данной политической партией

- добровольных пожертвований граждан и юридических лиц;

- $\quad$ средств, выделенных кандидату, избирательному объединению соответствующей избирательной комиссией, в случае, если это предусмотрено законом ${ }^{7}$ Федеральным законом «О политических партиях», напротив, перечень источников формирования партийных бюджетов является открытым. Согласно сводным финансовым отчетам политических партий за последние несколько лет, основными источниками при-

\footnotetext{
${ }^{6}$ См.: И. Борисов, С. Заславский, Партии на выборах. М.: 2007, издательство «Европа». С. 96-103

${ }^{7}$ См.: СЗ РФ, 17.06.2002, N 24, ст. 2253.
}

влечения финансовых ресурсов стали: государственное финансирование и пожертвования. Значительно меньшее влияние играют сегодня доходы от вступительных и членских взносов, гражданско-правовых сделок, предпринимательской деятельности. Некоторые политические партии широко используют «иные, не запрещенные законом» источники финансирования текущей деятельности партий. Примером может служить Политическая партия «Патриоты России», чей бюджет 2011 года на 75\% был сформирован из средств, привлеченных по договорам займа и на 38\% - в 2012 году. Более того, единственным кредитором партии выступил Семигин Геннадий Юрьевич, являющийся лидером партии ${ }^{8}$. С точки зрения действующего законодательства никаких нарушений в использовании подобных способов финансирования нет.

Необходимо отметить, что добровольные пожертвования, вносимые физическими и юридическими лицами, являются источником, как финансирования избирательных кампаний политических партий, так и текущего партийное финансирование. Законодательством предусмотрены единые ограничения на возможность отдельных категорий лиц осуществлять пожертвования. Прежде всего, речь идет о запрете на привлечение пожертвований политическими партиями со стороны иностранных государств, иностранных юридических лиц, иностранных граждан, лиц без гражданства, международных организаций и международных общественных движений, что является оправданным, принимая во внимание политическую и общественную значимость политических партий. Запрещается партиям получать финансовую и иную помощь партиями от российских юридических лиц с иностранным участием, доля (вклад) которого в уставном (складочном) капитале таких юридических лиц на день внесения пожертвования превышает 30 процентов. Если юридическое лицо является открытым акционерным обществом, то доля участия иностранного лица определяется на день составления списка лиц, имеющих право участвовать в годовом общем собрании акционеров за предыдущий финансовый год. Более того если такие юридические лица вносили в течение года предшествующего дню внесения пожертвования политической партии или ее региональным отделениям, денежные средства либо иное имущество в бюджет некоммерческие организаций, то партии не вправе принимать пожертвования от последних. Правом финансовой помощи политическим

\footnotetext{
${ }^{8}$ См.: Сводный финансовый отчет Политической партии «Патриоты России» за 2011 год//http://cikrf.ru/politparty/finance/2011/ patrioty.PDF
} 
DOI: $10.7256 / 1811-9018.2013 .11 .9855$

При цитировании этой статьи сноска на ооі обязательна

\section{Право и политика 11 (166) • 2013}

партиям не обладают некоммерческие организации, получавшие в течение указанного выше периода денежные средства или иное имущество от иностранных государств, организаций, учрежденных государственными органами и (или) органами местного самоуправления и иных, предусмотренных ст. 30 Федерального закона «О политических партиях» 9

Граждане Российской Федерации, не достигших возраста 18 лет, не вправе вносить пожертвования политическим партиям. Можно предположить, что данный запрет связан с вопросов достижения граждан полной дееспособности, то есть способности совершать любые сделки, не запрещенные законом. Однако Гражданский Кодекс предусматривает случаи, когда граждане могут приобрести полную дееспособность до достижения ими 18 летнего возраста, а именно при вступлении в брак до 18 лет или при принятии на работу по трудовому договору, а также при осуществлении предпринимательской деятельности с согласия родителей. Но для приобретения активного избирательного права гражданин должен достичь 18 лет, а так как основной целью деятельности политических партий все же является участие ее в выбоpax, вследствие чего, она может формировать и влиять на политику государства, то подобное ограничение для внесения пожертвований представляется разумным.

Помимо указанных ограничений, законом закрепляется запрет на получение пожертвований со стороны органов государственной власти, иных государственных органов, органов местного самоуправления, воинских частей, военных организаций, правоохранительных органов, государственных и муниципальных учреждений, государственных и муниципальных унитарных предприятий, юридических лиц, в уставном (складочном) капитале которых доля (вклад) Российской Федерации, субъектов Российской Федерации и (или) муниципальных образований превышает 30 процентов на день внесения, организаций, учрежденных государственными органами и (или) органами местного самоуправления. Государственные и муниципальные органы и учреждения, а также юридические лица с государственным и муниципальным участием не в праве жертвовать политическим партиям, так как в данном случае идет речь о перераспределении государственных средств ${ }^{10}$. Также государство обязано соблюдать принцип равноправия всех политических

${ }^{9}$ См.: С3 РФ, 16.07.2001, №29.Ст.2950

${ }^{10}$ Научно-практический комментарий к Федеральному закону «Об основных гарантиях избирательных прав и права на участие в референдуме граждан Российской Федерации». Коллектив авторов// www.cikrf/law/federal_law/comment/ партий и не вправе отдавать предпочтение отдельным из них, посредством перечисления пожертвований.

Спорным представляется размер максимально допустимой доли участия государства в уставном (складочном) капитале в 30\%. Если законодатель опасался того, что такие лица могут быть зависимы от государства, муниципального образования, то размер доли должен был быть равен 20\%. Так как согласно Гражданскому Кодексу России хозяйственное общество является зависимым, если другое общество имеет более $20 \%$ голосующих акций или уставного капитала для ОАО и ООО соответственно. Налоговый Кодекс содержит понятие взаимозависимых лиц, согласно которому физические и юридические лица взаимозависимы, если отношения между ними могут оказывать влияние на условия или экономические результаты их деятельности или деятельности представляемых ими лиц ${ }^{11}$, в том числе на решения об осуществление тех или иных сделок. А так как передача пожертвований, как в виде денежных средств, так и в натуральной форме, является сделкой, то представляется необходимым отдельно обратить внимание на размер доли, при наличии которой существуют основания говорить о взаимозависимости лиц. Законодатель предусмотрел ряд критериев признания лиц взаимозависимыми. Такими, помимо прочего, являются организации, если одна организация прямо или косвенно участвует в другой и доля такого участия более $25 \%$. Представляется необходимым снизить пороговое значение доли участия в капитала юридического лица и предусмотреть запрет на осуществление пожертвований со стороны юридических лиц, доля иностранного участия или доля Российской Федерации, субъектов Российской Федерации и/или муниципальных образований в уставном капитале которых более или равна $20 \%$.

Отдельно стоит обратить внимание на тот факт, что запрещается получать пожертвования от благотворительных организаций и религиозных объединений, а также от учрежденных ими организаций. Это же положение подтверждается и в Ф3 от 11.08.95 №135-Ф3 «О благотворительной деятельности», где в п.5 ст.12 закреплено, что благотворительная организация не вправе расходовать свои средства и использовать свое имущество для поддержки политических партий ${ }^{12}$. Дело в том, что значительная часть их имущества формиру-

\footnotetext{
${ }^{11}$ См.: С3 РФ №31. 03.08.1998. ст.3824

${ }^{12}$ Братановский С.Н., Рождествин А.А. Комментарии к Федеральному закону О политических партиях №95-Ф3 от 11 июля 2001 (в ред. Федерального закона от 03.11.2010) // http://www.lawmix.ru
} 


\section{Системы стабилизации: финансовый контроль}

ется за счет благотворительных пожертвований, и такой запрет обеспечивает целевое расходование пожертвований. Также благотворительные организации обладают рядом налоговых и иных льгот, и преимуществ, что позволяет говорить о том, что они получают косвенную государственную поддержку (ст.15).

Россия является светским государством, согласно Конституции, что означает, что ни одна религия не может быть установлена в качестве государственной или основной, а все религиозные объединения отделены от государства и равны между собой. В развитие данного положения выступает и Федеральный закон «О свободе совести и вероисповедания», закрепляя, что в соответствии с вышеуказанным принципом, религиозные организации не вправе участвовать в деятельности политических партий, оказывать им материальную или иную помощь.

Для целей обеспечения прозрачности партийного финансирования важным является недопущение получения финансовой поддержки партиями от так называемых фирм «однодневок», то есть юридических лиц, которые создаются с единственной целью - передача денежных средств политическим партиям. Благодаря этому истинные доноры могут оставаться в тени ${ }^{13}$. Потому, законодательством установлено, что юридическое лицо должно быть зарегистрировано не менее, чем за год до дня внесения пожертвований. Существует запрет на получение пожертвований от анонимных жертвователей. Под анонимным жертвователем понимается гражданин, который не указал в платежном документе на внесение пожертвования любое из следующих сведений: фамилию, имя и отчество, адрес места жительства - или указал недостоверные сведения. Если жертвователем является юридическое лицо, то оно будет рассматриваться как анонимный жертвователь при не раскрытие в платежном документе на внесение пожертвования любого из следующих сведений: идентификационный номер налогоплательщика, наименование, банковские реквизиты - или указаны недостоверные сведения.

Отличием текущего финансирования от финансирования избирательных фондов является ограничения, предусмотренные в отношении размеров привлекаемых финансовых средств. Действующим законодательством ограничивается предельные размеры пожертвований, привлекаемых партией за год всего, от одного юридического и физического лица. Согласно Федеральному закону «О политических партиях», привлеченные финансовые средства за

\footnotetext{
${ }_{13}$ Деньги партии, вопросы безопасности. 11.10.12//www.qsec.ru
}

календарный год в форме пожертвований не могут быть более 43,3 млн. рублей для политической партии и 86,6 млн. рублей для регионального отделения. Закрепление в законе максимального размера привлекаемых в форме пожертвований финансовых средств, безусловно, является необходимым и своевременным для обеспечения прозрачности финансирования партий. Однако, учитывая уровень привлекаемых финансовых средств политическими партиями в качестве пожертвований, можно говорить о фактическом отсутствии ограничений для партий в отношении максимально допустимого размера сумм привлекаемых пожертвований партией за год. Согласно финансовым отчетам политических партий России за 2012 год партия, обладающая наибольшими финансовыми ресурсами - Единая Россия - привлекла около 2,5 млрд. рублей всего, из которых пожертвования составили менее 1 млрд. рублей. Более того, общий размер пожертвований, привлеченных 7 политическими партиями ${ }^{14}$ за 2012 год составляет 1 млрд. 590 млн. рублей, что более, чем в 2 раза меньше установленного максимума на общий размер привлекаемых пожертвований одной политической партией за год. Таким образом, можно говорить о том, что установление столь высокого порогового значения ограничений на размер привлечение пожертвований не соответствует целям обеспечения и гарантии финансовой независимости партий от жертвователей.

Общей размер денежных средств, которыми располагает партия с учетом поступлений из иных разрешенных источников, не являющихся пожертвованиями (членские взносы, доходы от предпринимательской деятельности, гражданско-правовых сделок и т.д.), закон не ограничивает. В то время как для избирательных фондов устанавливается иной порядок определения максимального размера избирательного фонда, а также определения доли источников привлечения финансовых средств. Основой для исчисления максимально допустимого размера финансирования служит предельная сумма всех расходов из средств избирательного фонда политических партий, их региональных отделений. Согласно Федеральному закону от 18.05.2005 №51-Ф3 (ред. от 02.07.2013) «О выборах депутатов Государственной Думы Федерального Собрания Российской Федерации»

\footnotetext{
${ }^{14}$ В данном случае рассматриваются крупнейшие политические партии, пользующиеся достаточно высокой степенью доверия избирателей, успешно действующие на протяжении длительного времени, а, следовательно, обладающие значительными возможностями для привлечения финансовых средств в форме пожертвований от физических и юридических лиц.
} 
DOI: $10.7256 / 1811-9018.2013 .11 .9855$

При цитировании этой статьи сноска на dоі обязательна

\section{Право и политика $11(166) \cdot 2013$}

предельная сумма всех расходов политической партии из средств избирательного фонда политических партий составляет не более 700 млн. рублей. ${ }^{15}$ Федеральный закон от 10.01.2003 №19-Ф3 (ред. от 02.07.2013) «О выборах Президента Российской Федерации» подобное ограничение является еще более строгим и составляет не более 400 млн. рублей. ${ }^{16}$ Еще одним отличием двух видов финансирования политических партий заключается в том, что не израсходованные привлеченных средств для осуществления текущей деятельности остаются в собственности политической партии. В отношении неизрасходованных средств на избирательную кампанию действует иное правило - они должны быть возращены жертвователям пропорционально их вкладам.

Текущее финансирование политических партий в значительной мере отличается от финансирования избирательных кампаний по целям возможного использования привлеченных средств. Согласно п. 3 ст. 59 Федерального закона от 12.06.2002 № 67-Ф3 (ред. от 07.05.2013) «Об основных гарантиях избирательных прав и прав на участие в референдуме граждан Российской Федерации» ${ }^{17}$ средства избирательного фонда, в отличие от средств, предназначенных на осуществление текущей деятельности, имеют строгое целевое назначение. Их расходование возможно лишь на покрытие расходов, связанных с проведением своей избирательной кампании, а именно, на:

а) финансовое обеспечение организационно-технических мер, направленных на сбор подписей избирателей, участников референдума в поддержку выдвижения кандидата, инициативы проведения референдума, в том числе на оплату труда лиц, привлекаемых для сбора подписей избирателей, участников референдума;

б) предвыборную агитацию, агитацию по вопросам референдума, а также на оплату работ (услуг) информационного и консультационного характера;

в) оплату других работ (услуг), выполненных (оказанных) гражданами или юридическими лицами, а также на покрытие иных расходов, непосредственно связанных с осуществлением своей деятельности.

В отношении финансирования текущей деятельности политических партий действует иной подход. Партиям предоставляется финансовая самостоятельность в рамках, предусмотренных законодательством Российской Федерации. Финансовые средства политических партий могут быть израсходованы на осущест- вление текущей деятельности, необходимой для достижения своих целей и задач. Более того, собственные средства могут быть использованы для формирования избирательных фондов политических партий и/или кандидатов, выдвинутых данной политической партией в размерах, установленных законодательством.

Сегодня законодательство в области регулирования финансирования политических партий во многом соответствует международным нормам и стандартам. Однако оно характеризуется громоздкостью, в том смысле, что данные вопросы регулируются значительным количеством различных нормативно-правовых актов, что в свою очередь приводит к определенным трудностям право применения. Более того, различия между рассмотренными видами партийного финансирования представляются значительными. Представляется целесообразным разработать единый нормативно-правовой акт, сферой регулирования которого стали бы вопросы партийного финансирования.

\section{Библиография:}

1. Борисов, И., Заславский, С.Е. Партии на выборах/ И. Борисов, С.Е. Заславский.-М.: Европа, 2007. $128 \mathrm{c.}$

2. Братановский С.Н., Рождествин А.А. Комментарии к Федеральному закону О политических партиях №95-Ф3 от 11 июля 2001 (в ред. Федерального закона от 03.11.2010) // http://www.lawmix.ru

3. Casas-Zamora K. Paying for Democracy: Political Finance and State Funding for Parties. - the UK University of Oxford: ESPR, 2005. - 290 p.

\section{References (transliteration):}

1. Borisov, I., Zaslavskii, S.E. Partii na vyborakh/ I. Borisov, S.E. Zaslavskii.-M.: Evropa, 2007. - 128 s.

2. Bratanovskii S.N., Rozhdestvin A.A. Kommentarii k Federal'nomu zakonu O politicheskikh partiyakh №95-FZ ot 11 iyulya 2001 (v red. Federal'nogo zakona ot 03.11.2010) // http://www.lawmix.ru

3. Casas-Zamora K. Paying for Democracy: Political Finance and State Funding for Parties. - the UK University of Oxford: ESPR, 2005. - 290 p.

\footnotetext{
${ }^{15}$ См.: СЗ РФ, 23.05.2005, N 21, ст. 1919,

${ }^{16}$ См.: СЗ РФ, 13.01.2003, N 2, ст. 171

${ }^{17}$ См.: СЗ РФ 17.06.2002. № 24. Ст. 2253
} 